$\begin{array}{lcl}\text { Bentham OPen } & \text { The Open Transportation Journal } \\ \text { CrossMark } & \text { Content list available at: www.benthamopen.com/TOTJ/ } \\ \text { DOI: } 10.2174 / 1874447801610010057 & \text { Then }\end{array}$

\title{
High-Speed Rail for Freight: Potential Developments and Impacts on Urban Dynamics
}

\author{
Mathieu Strale* \\ Université Libre de Bruxelles- Institut de gestion de l'environnement et d'aménagement du territoire (IGEAT-ULB), \\ unité de géographie appliquée et de géomarketing, Avenue F. D. Roosevelt, 50, CP 130/03 1050 Bruxelles Belgique
}

\begin{abstract}
At present, high-speed rail is used only as a mode of passenger transport. Yet, the acceleration of logistics and freight transport flows could be compatible with high-speed rail capabilities. This article examines the experiences, literature and prospects of high-speed rail for freight. It uses three hypotheses to evaluate the development of freight high-speed rail services in Europe. The article concludes by describing the potential impacts on urban dynamics. It appears that the potential of freight high-speed rail services is limited in Europe, because of logistical constraints and network capabilities. Nevertheless, policies followed in Europe may change the situation.
\end{abstract}

Keywords: Europe, Freight transportation, High speed rail, Urban logistics.

\section{INTRODUCTION}

The development of high-speed rail (HSR) services raises the question of its potential use for freight transport. Indeed, not only passengers are concerned by the acceleration of flows. The growth of express mail services and ecommerce are good examples of the need for fast services dedicated to goods exchanges, both within Europe and globally. In this context, there has been research and operational experimentation on the use of HSR for freight. However, with the exception of "La Poste" in France, high-speed rail has remained limited to passenger transport.

Our analysis is based on two questions:

- Why are there so few freight HSR services?

- If HSR was used for freight, what could be the dynamics on urban spaces?

Given that some air freight companies and public authorities are seeking freight development on HSR networks, it is quite disturbing that the service has not gained traction. Is it an infrastructure issue? Are HSR companies not interested in freight services? Is the potential market too small?

It is clear that the development of HSR freight services will affect urban spaces: better urban logistics, relocation of mail services and related activities, attraction of new enterprises or development of new freight terminals. These impacts must be identified and described.

In response to these issues, the analysis describes the current and future projects on the development of high-speed rail for freight, by examining the scientific literature and institutional or commercial publications. The economic, operational and political opportunities and difficulties that these projects face are presented. We identify the adaptation (or lack thereof) of HSR for the main supply chains: retail delivery, express transport, international and industrial

\footnotetext{
* Address correspondence to this author at the Université Libre de Bruxelles- Institut de gestion de l'environnement et d'aménagement du territoire (IGEAT-ULB), unité de géographie appliquée et de géomarketing Avenue F. D. Roosevelt, 50, CP 130/03 1050 Bruxelles Belgique; E-mail: mstrale@ulb.ac.be
} 
logistics. This results in a critical synthesis of the main reasons of the rare use of HSR for goods transport. Based on these results and on the potential users of freight HSR, the potential effects on urban dynamics are analysed. The location and potential relocations of the clients and of the terminals and their impacts on urban spaces are then identified.

\section{The Current Situation About High-Speed Rail For Freight}

High-speed rail (HSR) is not used for carrying goods in Europe for the following reasons [1, 2]:

- Inadequate infrastructure: With the exceptions of some German and Spanish lines, high-speed tracks are designed for passenger services, not for heavy freight heavy trains. High-speed trains (HST) are not designed for carrying goods. Moreover, high-speed lines' (HSL) geography link major city centres. Freight activities locations are not connected by HSL.

- Inadequate exploitation: The management of HSL is focused on passenger services; for example many tracks are closed at night for maintenance. During the day, passenger trains have priority and some HSL are already congested.

- The high cost of HSR: Because of HSR technology, the required security measures and the cost of infrastructure, the cost of HSR use is very high.

- The absence of freight services: Since there is not best practice examples (with the exception of "La Poste"), the risk of launching a freight service is high.

Indeed, in 2014 the only freight HSR operator, the French mail company "La Poste" decided to stop this service because of the lack of goods and because of the additional cost [3]. For thirty years, between 6 and 8 high-speed trains per night transported mail between Paris, Mâcon and Cavaillon.

As of this writing, the only plan for using HSR for freight is the Euro-Carex project [4, 5]. This project links the major northwest European freight airports (Liège, Paris, Frankfurt, Koln, Amsterdam, Brussels and London) with freight HSR. This would allow the removal of flights between these airports and replacing them with long-haul services. Promoters of Euro-Carex are airport authorities, one airline (Air France-KLM), the French public mail company La Poste, and three major freight integrator companies, UPS, TNT and FedEx. This service is scheduled to launch in 2018. The first operational test began in 2012. They expect to carry around 800.000 tons per year or about 25 trains per day.

With this exception, at this time, there is no other project of HSR use for freight in Europe. However, there has been research in Europe and in the United States about the potential development of HSR for freight [1, 6, 7]. They highlight the difficulties of such developments.

This situation raises two questions:

- Which distribution patterns are compatible with the use of HSR?

- What is the potential in Europe?

\section{Urban Logistics Patterns and The Potential Use of High-Speed Rail}

One reason of the lack of use of HSR for freight may be its incompatibility with urban logistics requirements. Based on this hypothesis, the structure of the main urban distribution patterns has been analysed (Fig. 1). These are retail distribution, with the distinction among independent retailers, chain stores and supermarkets, tertiary activities logistics and e-commerce.

It appears that the only adapted logistics chains are those based on parcel distribution -- e-commerce and mail services. Indeed, these are light and small goods that may be carried in HST and that must be transported rapidly to their client, which is a potential advantage of HSR. In addition, distribution chains may be long because many of these products are ordered on the Internet. These are goods that are frequently carried by plane, because of their low weight and fast distribution requirement [8 - 10]. Thus, express mail operators are concentrated around main airports, which may facilitate the consolidation of flows on some rail services [11].

In contrast, conventional retail distribution is intended for heavier goods that go through distribution centres or wholesalers located in city suburbs $[2,12,13]$. So, final distribution is short. The only exception is chain stores. They may receive long-distance goods but their logistics are based on cost reduction and freight consolidation on European distribution centres. Their requirements are large transport capacities and low transport cost, neither of which is 
compatible with high-speed rail services.

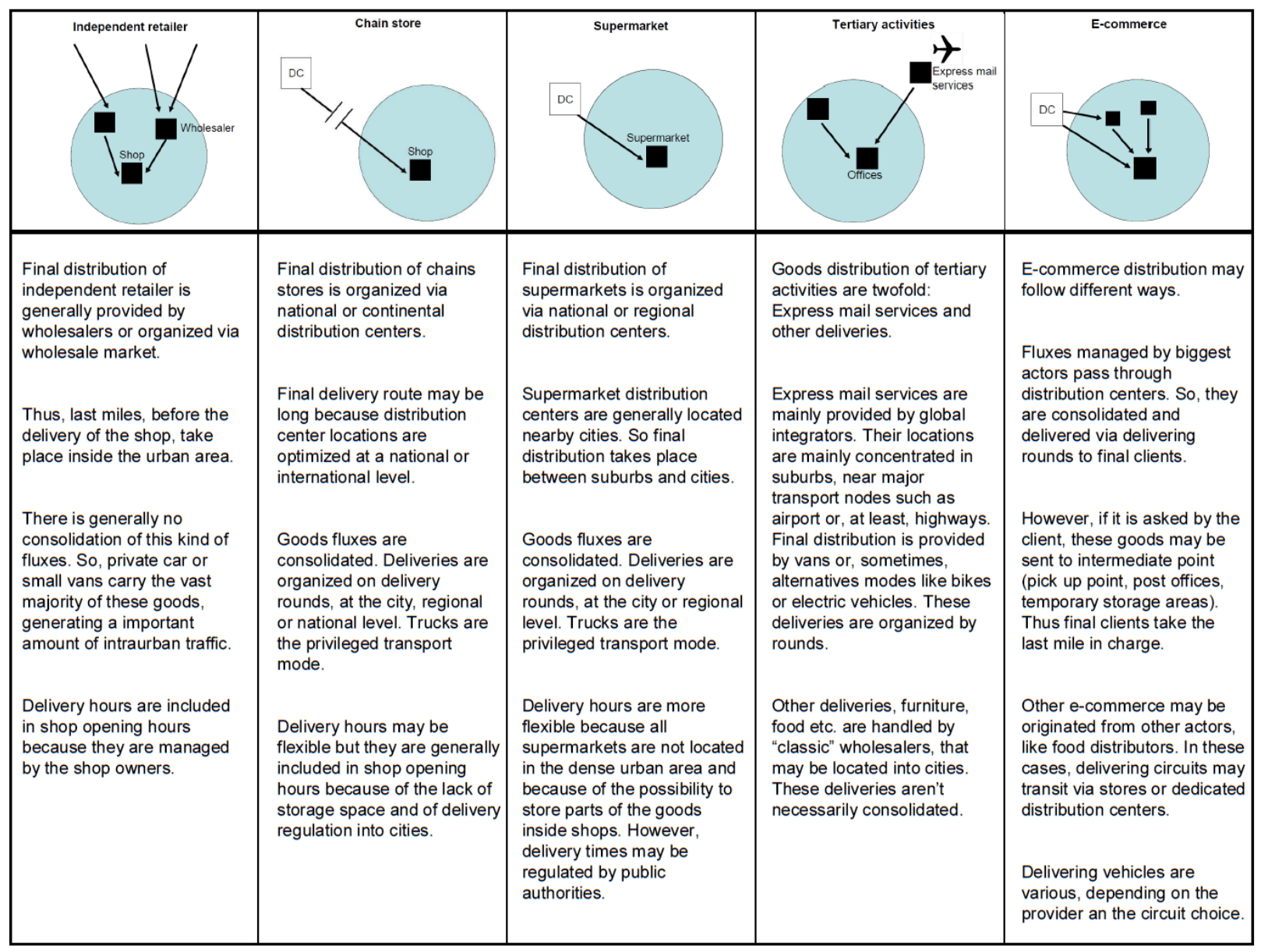

Sources: Fernie, 2009 \& 2010; Strale, 2013; Wayens, 2006.

Fig. (1). Major urban distribution patterns.

Another way of estimating the potential market of HSR services for freight is analysing the entire rail freight market (Fig. 2). It appears that the conventional market segment of rail freight consists of large volumes of raw materials, or heavy semi-finished or finished goods, carried over long distances [2]. Indeed, the competitive advantages of road transport are the high capacity of rail freight and its lower transport cost per kilometres than road transport. In contrast, rail freight transport has higher handling costs and less flexibility and reliability than road transport. Thus, conventional rail freight is uncompetitive for short distance and especially for urban logistics. High-speed rail, however is suited to daily parcel and mail services, because of its rapidity and reliability [1].

Thus, the best market for cargo HSR is parcel deliveries. It is growing sector, because of the development of ecommerce and of express deliveries. It is estimated that every European citizen creates a 150 kilo flow of parcels per year $[14,15]$. Moreover, tertiary services, that also need parcel deliveries, are concentrated in and around urban areas, where high-speed lines and stations are concentrated [8].

At this time, parcel delivery market is led by global integrators: TNT, DHL, UPS and FedEx [2]. They are organised around major continental airport hubs that are linked with smaller urban and regional hubs. This situation may be favourable for the development of HSR services, because of the small number of actors and hubs in this sector. So, the establishment of a cooperation between one of these operators and HSR service providers may generate sufficiently large parcel flows. This is the aim of the Eurocarex project. On the contrary, the concentration and the efficiency of the parcel delivery market may be an obstacle to the creation of new services or the entry of a new actor on the market, because of this oligopolistic situation. 


\begin{tabular}{l|lll}
\hline Market segment & Typical transport time & Typical frequency & $\begin{array}{l}\text { Dominating railway } \\
\text { service }\end{array}$ \\
\hline $\begin{array}{l}\text { Bulk market } \\
\text { - Raw materials }\end{array}$ & Less than one day & Continous & Unit-trains \\
\hline $\begin{array}{l}\text { Base market } \\
\text { - Raw materials } \\
\text { - Semi-finished } \\
\text { products }\end{array}$ & $\begin{array}{l}\text { National: Day 0-1 } \\
\text { International: Day 1-3 }\end{array}$ & $\begin{array}{l}\text { Daily } \\
\text { Several times / } \\
\text { week }\end{array}$ & Wagonload traffic \\
\hline $\begin{array}{l}\text { Product market } \\
\text { - Semi-finished } \\
\text { products }\end{array}$ & $\begin{array}{l}\text { Overnight } \\
\text { - Finished products }\end{array}$ & Daily & \\
\hline $\begin{array}{l}\text { Service market } \\
\text { - parcel and letter mail, } \\
\text { express cargo } \\
\text { - couriergoods }\end{array}$ & Same day & & Combined Traffic \\
\hline
\end{tabular}

Fig. (2). Rail freight markets.

Sources: Troche, 2005

Regarding the location of major European parcel hubs, some synergy may appear with the European HSR network. Indeed, current hubs are Paris Charles-de-Gaulle for FedEx, Liège for TNT, Koln Bonn airport for UPS and Leipzig for DHL [2]. All these cities are connected to the HSR network, but HSL to Leipzig is limited to 200-230kph. In addition, other major European freight airports such as London, Brussels, Frankfurt or Amsterdam are connected to HSL. Moreover, many of these airports are involved in the Eurocarex project [5].

Finally, in congested airports, such as London, Frankfurt or Amsterdam, a HSR freight service has at least two advantages. It may be more reliable than airfreight, because of the delays in these airports. In addition, it may reduce the number of flights on these hubs.

\section{The Potential of Freight HSR Services in Europe}

Having identified the potential market of HSR services for freight in Europe, the second issue is the kind of services that may be developed for carrying these goods. There are two potential patterns for developing HSR services (Fig. 3):

- The replacement of short-haul flights by HSR when airports are linked by existing HSL. This is the Eurocarex scheme;

- HSR can be the last distribution transport mean, in combination with air services.

For evaluating the European potential of these two schemes, a three-step scheme based on freight traffic of European airport has been proposed. Data come from the Eurostat database [16]. It is estimated that current HST may carry around 100 tons, close to the capacity of a Boeing 747, 3 Airbus A310 or 7 Boeing 737 [1, 4]. Thus, it is possible to estimate the amount of freight HST that would be necessary for carrying these goods.

In the first step, the potential of the Eurocarex scheme has been estimated, using data on freight traffic between airports. The analysis is based on the first exploitation scheme: HSR services that replace airfreight between airports.

In the second step, we have extended the Eurocarex scheme to all airports located in cities connected to HSR network. The hypothesis is that all airfreight carried between airports located in cities connected to HSL is replaced by HSR services.

In the third step, we have analysed the second potential market for HSR freight services: feeder services from and to main freight airports. Based on the current air freight traffic and the size of the parcel market in Europe, we have made some basic and exploratory estimations of these kinds of services. 


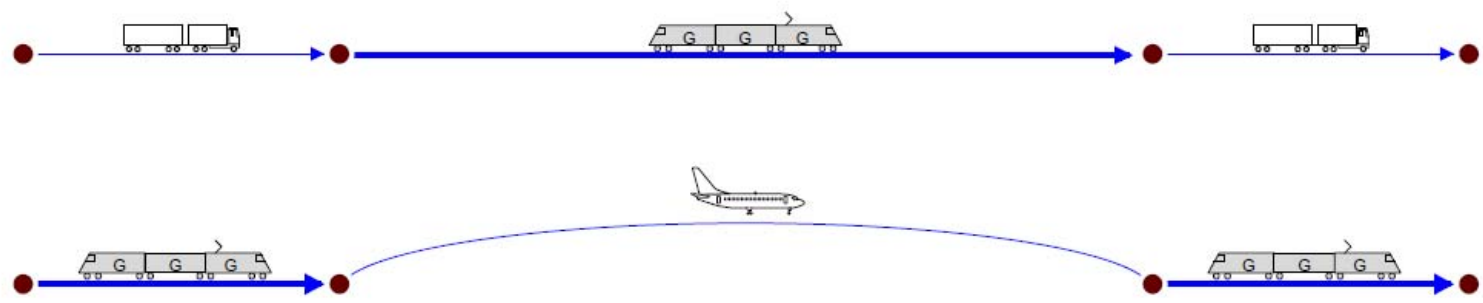

Sources: Troche, 2005

Fig. (3). Potential development schemes of freight high-speed rail services.

Table 1. Airfreight traffic between "Eurocarex" airports (tons per year, 2011).

\begin{tabular}{|c|c|c|c|c|c|c|c|c|c|c|}
\hline Bruxelles & & & & & & & & & & \\
\hline \multicolumn{11}{|l|}{ Liege } \\
\hline \begin{tabular}{|l} 
London \\
\end{tabular} & 7000 & 13000 & & & & & & & & \\
\hline Paris & & 3500 & 38000 & & & & & & & \\
\hline Lyon & 1700 & 4000 & & 5500 & & & & & & \\
\hline Bordeaux & & 300 & & 4600 & & & & & & \\
\hline Marseille & 1700 & 4000 & & 19600 & 1000 & & & & & \\
\hline Amsterdam & & & 5000 & 6700 & & & & & & \\
\hline Frankfurt & 1400 & & 23000 & 17000 & 100 & & & 6000 & & \\
\hline \multirow[t]{2}{*}{ Koln } & & & 35000 & 61000 & 12000 & 2900 & 11500 & & 4500 & \\
\hline & Bruxelles & Liege & London & Paris & Lyon & Bordeaux & Marseille & Amsterdam & Frankfurt & Koln \\
\hline
\end{tabular}

Sources: Eurostat, 2015

The evaluation of the potential of the Eurocarex scheme brings up the limited potential of the project (Tables $\mathbf{1}$ and 2). Indeed, even if the airports of the second step of the Eurocarex project (to be included around 2020), Bordeaux, Marseille and Lyon, are included in the evaluation, the total number of trains required for carrying this freight is below the aims of the partners of Eurocarex (6/8 trains per day).

The backbone of this project is the relation among Paris, London and Liege and Koln, with 15-20 trains per week on these relations (Fig. 4). There are fewer links to other airports.

Of course, an effective and competitive service for express mail and parcel services would at least one train each day or two $[1,2]$. With constant freight volume, this signifies that some trains would be nearly empty or that some airports should be excluded from the project.

Another possibility is the addition of hubbing services between HST for gathering flows coming from links with small amounts of freight. These hubs should be located at the economic and geographic centre of the project (e.g. Paris or Brussels). However, it would require new infrastructure and investments, additional costs and a longer delivery time, all of which are problematic with express deliveries.

Of course an efficient and attractive HSR freight service would attract new markets and clients, coming from conventional road mail deliveries or using it as a final means of distribution. Our analysis demonstrates the need to attract these new clients in order to make such a project profitable.

Another possibility is extending the range of the service, connecting all the airports located in cities already linked with HSL. This is our second suggestion. Additional airports are located in Germany, Italy, Spain and the UK (Fig. 5).

The analysis is based on the same hypothesis as the previous one: replacing all airfreight between connected airports by HSR services. 
Table 2. Potential freight high-speed trains between "Eurocarex" airports (trains per year, based on Eurostat)".

\begin{tabular}{|c|c|c|c|c|c|c|c|c|c|c|}
\hline Bruxelles & & & & & & & & & & \\
\hline Liege & 0 & & & & & & & & & \\
\hline London & 70 & 130 & & & & & & & & \\
\hline Paris & 0 & 35 & 380 & & & & & & & \\
\hline Lyon & 17 & 40 & 0 & 55 & & & & & & \\
\hline Bordeaux & 0 & 3 & 0 & 46 & 0 & & & & & \\
\hline Marseille & 17 & 40 & 0 & 196 & 10 & 0 & & & & \\
\hline Amsterdam & 0 & 0 & 50 & 67 & 0 & 0 & 0 & & & \\
\hline Frankfurt & 14 & 0 & 230 & 170 & 1 & 0 & 0 & 60 & & \\
\hline \multirow[t]{3}{*}{ Koln } & 0 & 0 & 350 & 610 & 120 & 29 & 115 & 0 & 45 & \\
\hline & Bruxelles & Liege & London & Paris & Lyon & Bordeaux & Marseille & Amsterdam & Frankfurt & Koln \\
\hline & 118 & 248 & 1210 & 1559 & 243 & 78 & 378 & 177 & 520 & 1269 \\
\hline
\end{tabular}

Sources: Eurostat, 2015

The results show the number of additional trains it is predicted to generate. However, with the exception of Leipzig, the DHL hub in eastern Germany, this additional traffic is rather limited. Indeed, major European freight airports and parcel hubs are already involved in the Eurocarex project.

In addition, it is doubtful that efficient HSR services crossing Europe, from Spain to Germany or from Italy to UK could be implemented, because of the poor connections between national HSR networks and the length of these links. This part of potential freight should be excluded from analysis, which would further reduce the potential market.

Another element is the fact that not all the airports are directly connected to HSL. The location of the new terminals is analysed in the next section.

Nevertheless, this second analysis demonstrates that a potential extension of the Eurocarex project should focus on Germany, especially on Leipzig.

Regarding the limited potential of the previous evaluations, one should consider the development of HSR services as feeder transport. Total freight traffic at Eurocarex airports reaches about 9 million tons per year (see Table 3). This is an enormous potential market. The final delivery of only 10 percent of these goods by HSR represents 1000 trips per year, approximately twice the estimated amount of airfreight between these airports only.

In addition, this is a fast-growing market $[14,15]$. However, to develop these services, the first step is the identification of the final destination of airfreight carried in these airports, what is strategic and private data. So, for now, only preliminary estimations can be carried out.

Nevertheless, freight HSR potential remains limited, and its development must take into account all of the difficulties that are highlighted in the first part of the analysis.

\section{Impacts on Urban Dynamics}

In light of the hypothetical development of HSR for freight, the evaluation of potential impacts on urban dynamics is theoretical and exploratory.

The main potential impact pertains to the location of mail and parcel services. The appraisal of a competitive service on express freight transport could affect the geography of these enterprises. At the European level, connected cities and airports would probably concentrate them at the expense of other places. Of course, related activities, like trucking, warehousing, freight forwarding could also relocate around the new nodes. Moreover, clients of parcel activities, such as business services could also be impacted. If new HSR freight services grow and become a real alternative for airfreight inside Europe, they may change the connectivity between cities. Thus, as airfreight did, it may change the hierarchy of cities regarding high-level services networks [17, 18], favouring connected cities. 


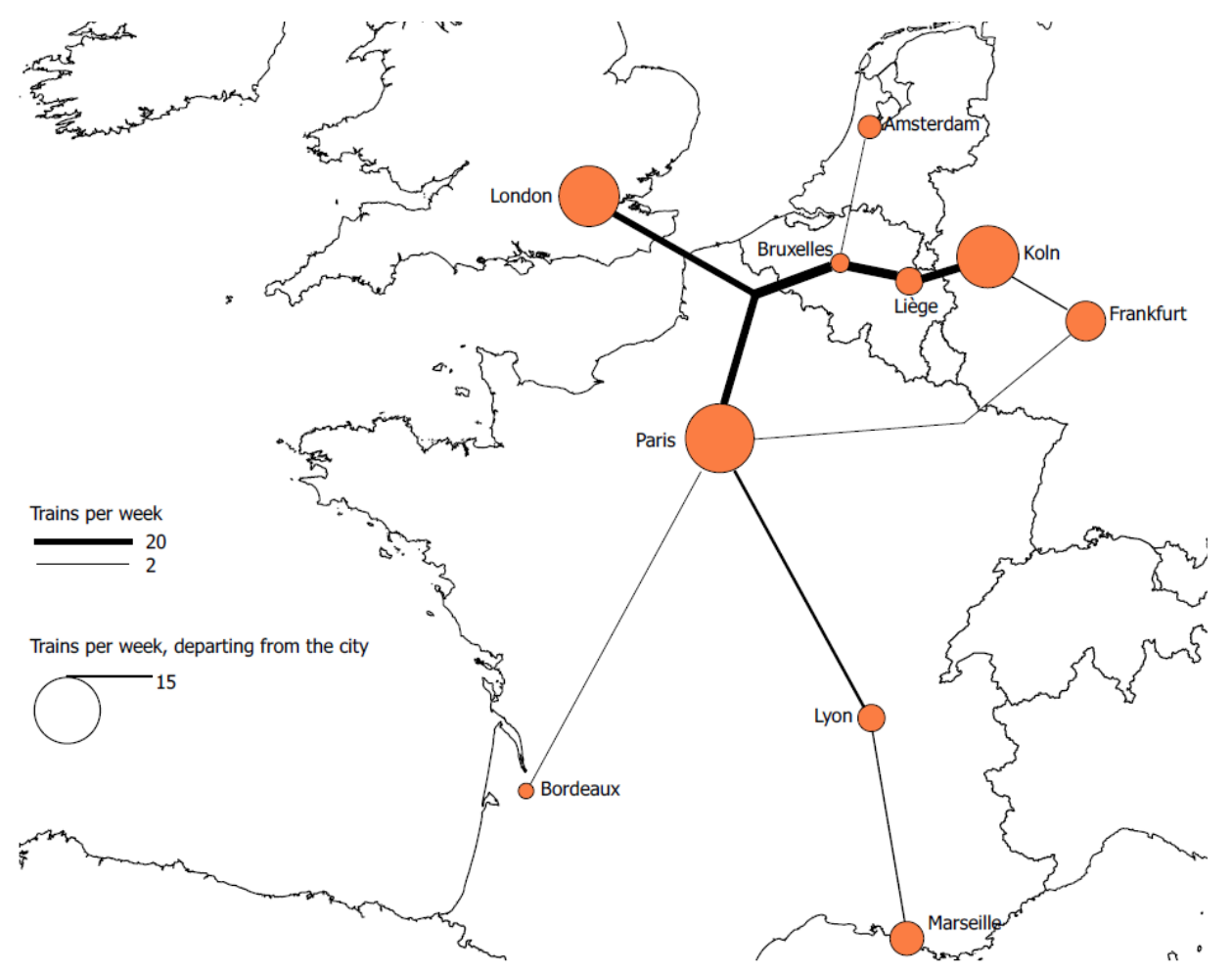

Sources: Eurostat, 2015; Eurocarex, 2015

Fig. (4). Estimation of the potential high-speed rail traffic of Eurocarex project.
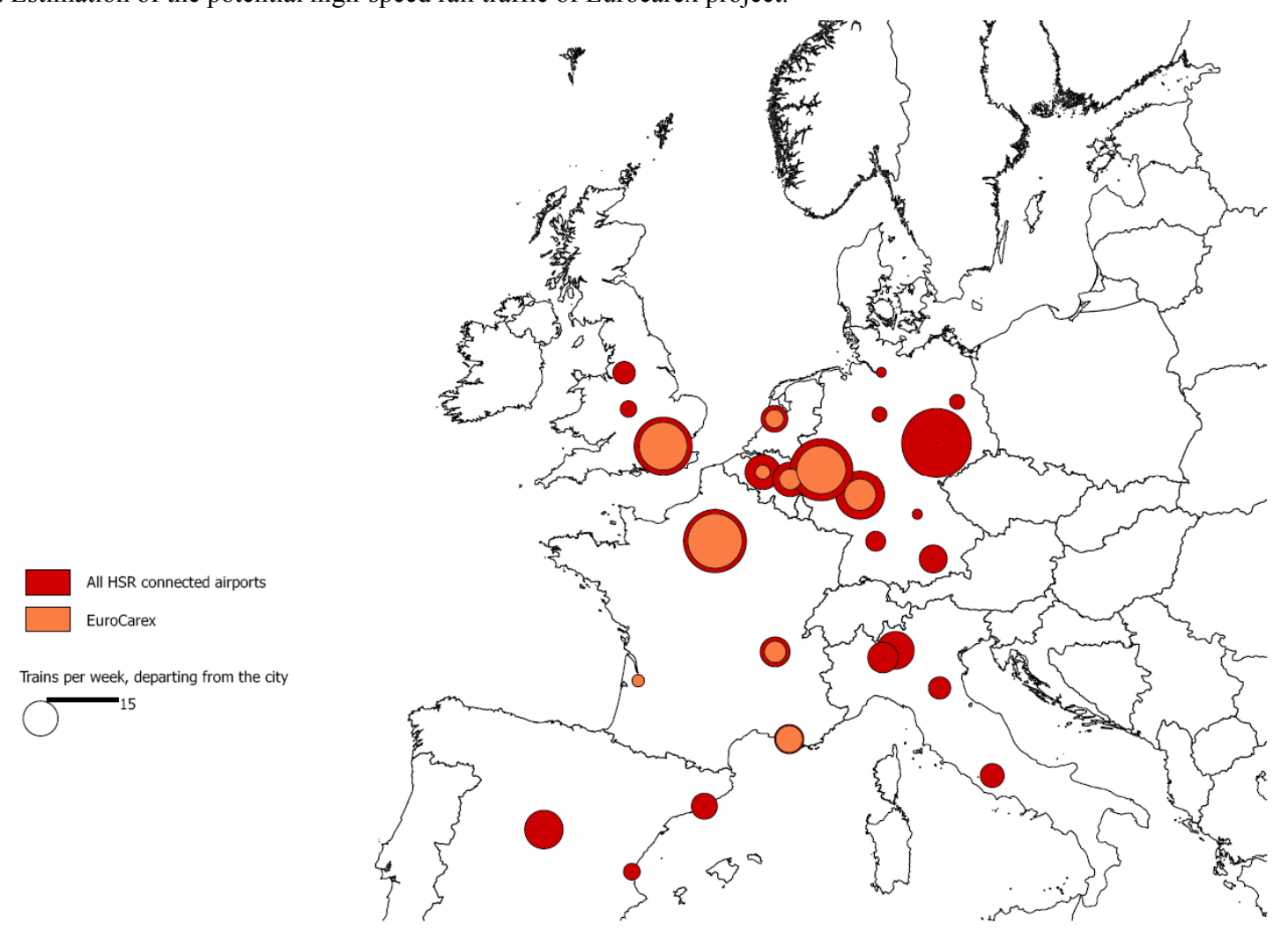

Sources: Eurostat, 2015; Eurocarex, 2015

Fig. (5). Estimation of the potential freight high-speed rail traffic in connected airports. 
At a more local and regional level, the issue is the location of new HSR freight terminals. The choice will probably be made between airport sites and urban passenger stations. An airport location facilitates the transit between airfreight and HSR freight and corresponds to the current location of logistics services. Thus, this seems to be the easiest solution from an organisational perspective. On the other hand, airports are not always connected to HSR networks. In this case, the development of a freight terminal could require major investments in new railway tracks. Developing freight terminals in current HSR urban station would not require these investments but it raises the questions of the availability of space for goods handling in dense urban areas and of the additional road freight traffic around these new terminals. Moreover, parcel activities would also need space around these urban stations. Thus, for now the first solution is favoured. Eurocarex project is based on the development of freight terminals near major airports.

Another question is the potential combination of freight and passenger services. It is clear that for peripheral or small to medium airports, passenger or freight HSR connections alone cannot be profitable. In this context, a combination of freight and passenger services may improve the profitability of such HSR connection and increase the frequency of trains, which is essential for both freight and for passenger services. This would also enhance the connectivity and the accessibility of such airports. This kind of mixed development could connect secondary cities to the HSR network and increase frequency on secondary lines. However, this would demand new investment in combined passenger and freight HST. Moreover, it would also need infrastructure investment in stations and new exploitation adaptations. Thus, this is a long-term project.

Table 3. Total freight traffic at Eurocarex airports (1000 tons per year)

\begin{tabular}{|c|c|c|c|c|c|c|c|c|}
\hline & 1990 & 1995 & 2000 & 2005 & 2011 & 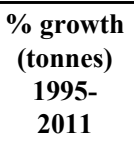 & $\begin{array}{c}\% \text { growth } 2000 \\
-2011 \%\end{array}$ & $\begin{array}{c}\text { No. of cargo } \\
\text { routes }\end{array}$ \\
\hline $\begin{array}{c}\text { Amsterdam } \\
\text { Schiphol }\end{array}$ & 604 & & 1222 & 1449 & 1523 & $152 \%$ & $25 \%$ & 91 \\
\hline London Heathrow & 695 & 1031 & 1307 & 1305 & 1484 & $44 \%$ & $14 \%$ & 80 \\
\hline Koln Bonn & & 312 & 423 & 636 & 726 & $132 \%$ & $72 \%$ & 70 \\
\hline Brussels & & 464 & 687 & 702 & 475 & $2 \%$ & $-31 \%$ & 51 \\
\hline Frankfurt & 1176 & 1521 & 1589 & 1892 & 2133 & $58 \%$ & $34 \%$ & 84 \\
\hline Paris Charles de Gaulle & & & 1517 & 1767 & 2088 & & $38 \%$ & 99 \\
\hline Liege & 0 & 0 & 270 & 325 & 674 & & $150 \%$ & 88 \\
\hline London Gatwick & & & 318 & 222 & 104 & & $-67 \%$ & 19 \\
\hline London Stansted & & & 260 & 254 & 204 & & $-22 \%$ & 37 \\
\hline Frankfurt Hahn & 0 & 0 & 25 & 107 & 286 & & $1044 \%$ & 17 \\
\hline
\end{tabular}

Sources: Eurostat, 2015

The last element pertains to the policy on new airport capacities released by the development of an HSR for freight. Here there are two options. The first option is to use these freed slots for developing new connexions, such as long-haul freight flights or passenger services. Indeed, these may be more profitable flights than European airfreight links, and may enhance the connectivity of airports. This is the aim of the initiators of Eurocarex. The second option is to formulate an ambitious environmental policy and to limit the number of flights in favour of rail connections. This would require a European-wide policy, something that is a medium or long-term projection.

\section{DISCUSSION}

This paper makes a threefold contribution.

First, the study identifies and demonstrates the obstacles to the development of freight high-speed rail services in Europe. These obstacles are economic, infrastructure, geographical and logistics.

In consequence, the only potential solution is the creation of HSR services for parcel and express mail transport between major airports and cities. It fits with the capacities of HSR: rapid transport, limited volumes, high-level and high-cost services. However, for now, only a few connexions between major European freight airports could generate enough freight to sustain a frequent freight HSR service. The only ongoing European project aims at developing such service. Nevertheless, other development and exploitation schemes may appear, but it will require more time and 
investment.

Second, there is a question about the effects of freight HSR on urban dynamics. Because of the novelty of the subject and the absence of realisation, only reflexion axes are drawn, based on the knowledge about urban dynamics, transportation and logistics. There are multi-level potential impacts, on the connectivity of cities, on the location of terminal within the agglomeration or on the transport policy in European cities and airports.

This raises the third contribution of this paper: the role of European policy. The development of a rail alternative to airfreight and its potential consequences for urban dynamics are closely related to the choices made on transportation, environmental and economic policy in Europe. For now, the competitive transportation market is favourable to road and air freight. Yet, more stringent policies on environmental impacts and costs, or on airport regulation could encourage the development of railway alternatives. In the same way, choices about location of terminals are main issues in urban policy.

\section{CONFLICT OF INTEREST}

The author confirms that this article content has no conflict of interest.

\section{ACKNOWLEDGEMENTS}

Declared none.

\section{REFERENCES}

[1] G. Troche, "High-speed rail freight", In: Sub-Report in Efficient Systems for Freight Transport. KTH Railway Group Report 0512: Stockholm, 2005.

[2] J-P. Rodrigue, M. Hesse, C. Comtois, and B. Slack, The Geography of Transport Systems, $3^{\text {rd }}$ ed. Routledge: New York, 2013.

[3] "Les échos, La poste arrête les TGV pour transport le courrier mais reste fidèle au rail", In: Les échos . Paris, 2014.[Accessed: 19/06/2014]

[4] "Urocarex, Euro Cargo Express", Project of High-Speed European Rail Freight Service Connected to Airports and Logistics Areas, 2011. Available from: http://www.eurocarex.com/pdf/pressreview/100103240178_carex-pressreview.pdf

[5] "Eurocarex", Website of Eurocarex, 2015. Available from: www.eurocarex.com/?setlang=en [Accessed: 19/05/2015].

[6] J.A. Pazour, R.D. Meller, and M.L. Pohl, "A model to design a national high-speed rail network for freight distribution", Transp. Res. Part A Policy Pract., vol. 44, no. 3, pp. 119-135, 2010. [http://dx.doi.org/10.1016/j.tra.2009.11.006]

[7] M.F. Ziolkowski, "The ties that bind: freight and passenger high-speed rail are interdependent", J. Transp. Geogr., vol. 22 , pp. 292-294, 2012. [http://dx.doi.org/10.1016/j.jtrangeo.2012.01.017]

[8] M. Hesse, "Shipping news: the implication of electronic commerce for logistics and freight transport", Resour. Conserv. Recycling, vol. 36, pp. 211-240, 2002. [http://dx.doi.org/10.1016/S0921-3449(02)00083-6]

[9] W.P. Anderson, L. Chatterjee, and T.R. Lakshmanan, "E-commerce, transportation and economic geography", Growth Change, vol. 34, no. 4, pp. 415-432, 2003. [Accessed 19/05/2015]. [http://dx.doi.org/10.1046/j.0017-4815.2003.00228.x]

[10] B. Wayens, "Structure et dynamique du commerce de détail bruxellois", Thèse de doctorat en Sciences, à l'Université Libre de Bruxelles, 2006.

[11] M. Strale, "La logistique: localisation des activités et impacts territoriaux", Thèse de doctorat en Sciences, présentée à l'Université Libre de Bruxelles, sous la direction de C. Vandermotten et M. F. Godart, 2013.

[12] J. Fernie, and L. Sparks, "Retail logistics, Changes and challenges in "Fernie J", In: Logistics and Retail Management: Emerging Issues and New Challenges in the Retail Supply Chain . London, 2009.

[13] J. Fernie, L. Sparks, and A.C. McKinnon, "Retail logistics in the UK: past, present and future", Int. J. Retail Distrib. Manag., vol. 38, no. 11/12, pp. 894-914, 2010. [http://dx.doi.org/10.1108/09590551011085975]

[14] "ARCEP - Autorité de Régulation des Communications Electroniques et des Postes", In: Observatoire annuel des activités productives en France, Année. 2012.

[15] Communication de l'IBTP du 22 janvier 2013 concernant l'observatoire du marché des activités postales en Belgique pour 2010 et 2011. 2013.

[16] "Eurostat", Eurostat Database, 2015. Available from: http://ec.europa.eu/eurostat/data/database. [Accessed: 19/05/2015].

[17] J. Beaverstock, R. Smith, and P. Taylor, "A roster of world cities", Cities, vol. 16, no. 6, pp. 445-458, 1999. [http://dx.doi.org/10.1016/S0264-2751(99)00042-6] 
[18] W. Jacobs, C. Ducruet, and P. de Langen, "Integrating world cities into production networks: the case of port cities", Glob. Netw., vol. 10, no. 1, pp. 92-113, 2010.

[http://dx.doi.org/10.1111/j.1471-0374.2010.00276.x]

\section{C) Mathieu Strale; Licensee Bentham Open.}

This is an open access article licensed under the terms of the Creative Commons Attribution-Non-Commercial 4.0 International Public License (CC BY-NC 4.0) (https://creativecommons.org/licenses/by-nc/4.0/legalcode), which permits unrestricted, non-commercial use, distribution and reproduction in any medium, provided the work is properly cited. 